\title{
Study on Regional Culture and Interactive Eco- social Development of Zhuhai-Macao in Big Data Era
}

\author{
Fan Chenxi \\ Hengqin Development Research Center \\ Zhuhai College of Jilin University \\ Zhuhai, P.R.China \\ 154909@qq.com
}

\begin{abstract}
To promote the cooperation of Zhuhai-Macao in Big Data era, it is important not only to find out the present critical problems and major reasons from the complex history and realities, but also to put forward new feasible solutions based on the numerous research results. We collect relevant information as much as possible, build Zhuhai-Macao Research Database, and take advantage of the Big Data mining technology such as data attribute label, data fragmentation, data analysis and data statistics for the mass data. Our recent research drew the conclusions that Zhuhai-Macao had the same cultural root and a long history of cooperation; what's more, the regional culture of Zhuhai-Macao played a decisive role and had important influence on the interactive eco-social development between them. However, we found some new problems and contradictions such as transformation of Zhuhai-Macao government slowly, cooperation of Zhuhai-Macao government poorly, integration of Zhuhai-Macao incautiously and talents management of Zhuhai-Macao insufficiently too. Our results show that the Zhuhai-Macao cooperation and development needs to be based on their respective cultural characteristics and consider their own distinguishing cultural features, and the research needs to utilize the Big Data mining and other information technology fully, moreover, we should do research scientifically, analyze deeply and adjust the coping strategies continuously to adapt to the world changing constantly.
\end{abstract}

Keywords-Zhuhai-Macao; regional culture; interactive ecosocial development; Big Data

\section{INTRODUCTION}

For a city's economic development, in the short term the economic investment and the infrastructure construction can play a certain promoting role, but the long-term development depends upon the profound cultural deposits. Culture is the soft power of city development, and it includes culture thoughts, culture philosophy, culture essence, culture pursuit, culture development, culture cooperation and so on. Culture is rooted in the history, affects the nowadays, and decides the future.

Supported by the 2014 Hong Kong and Macao Research Project Fund from the Chinese Association of Hong Kong and Macao Studies (Grant No. HKM1407); the 2014 Work Innovation Project Fund on the subject of ideological and political education from the Dep. of Guangdong Education (Grant No. 2014ZK003); and the 2014 Research Project of the Twelfth Five Year Plan from Zhuhai Federation of Social Science (Grant No. 2014126)

\author{
Han Songyang \\ Shenzhen Training and Research Center \\ Liaison Office of the Central People's Government in the \\ Hong Kong S.A.R \\ Shenzhen, P.R.China
}

Zhuhai and Macao are adjacent with each other closely. Zhuhai-Macao shares the same cultural root, owns the common ancestor, and has a long history of cooperation. Although there are many similarities between them, the differences in development history and growth process make them have diverse characteristic and distinct feature. In the age of Big Data, with the continuous eco-social development and technology progress, the eco-social cooperation of Zhuhai-Macao is facing new problems and new challenges. The similarities and differences between Zhuhai and Macao make them be faced with new contradictions and be fronted with new tasks. In such a new period, based on their respective characteristic of culture, it is very important that repositioning the interactive development strategies on the eco-social cooperation in Zhuhai-Macao.

\section{Cultural Characteristics of ZhUhai AND MACAO}

\section{A. Culture of Zhuhai}

Zhuhai lies in the south of Guangdong Province, the west coast of Pearl River Estuary and the southeast coast of China. Zhuhai is one of the important stations of maritime Silk Road in the ancient times. In addition Zhuhai is one of the central cities on the west coast of the Pearl River Delta and one of the important cities which Guangdong Province focuses on the development at present. The peculiar geography position, the special long-standing history, and the unusual development process makes Zhuhai form a unique splendid culture.

Zhuhai has marine culture of a long history. In the late primitive society about 4000-5000 years ago, Chinese ancient humans lived in the coast of Zhuhai area and invented the ancient sailing. From the Han and Tang Dynasties to the Ming and Qing Dynasties, Zhuhai always was important hub of East-West marine trade. Now Zhuhai port which includes Gaolan Port Area mainly and Jiuzhou Port Area secondarily is one of the 25 major coastal ports in China.

Zhuhai has open culture of reformation and innovation. From the late Qing Dynasty to the beginning of the republic, Zhuhai is the originating city of modern national industry and commerce. For example, the people of Zhuhai made the first 
locomotive, built the first railway, established the first mechanical coal mining company and set up the first cement factory in China [1]. After the reform and opening of China, Zhuhai is the first area of the Chinese economic reform, as well as is a breakthrough for the development of local economy. For instance Zhuhai founded the first foreignfunded enterprise, constructed the first Sino-foreign cooperation hotel, and established the first Sino-foreign cooperation real estate project in China [2].

Zhuhai has special region culture of system innovation. In the modern times there were a lot of celebrities who came from Zhuhai. They studied aboard and learn western knowledge to bring in western advanced technology and rescue the old China. Among them, there was the Father of Chinese Overseas Student Ronghong, the forerunner of the Westernization Movement Tangtingshu and the first Prime Minister of the Republic of China Tangshaoyi [3]. Zhuhai is one of the 4 Special Economic Zones where China implements the opening-up policy earliest and Zhuhai Special Economic Zone was established in 1980. The Zhuhai University Park was established in 1998. Now there are more than 120,000 college students in the park and Zhuhai becomes the second big city of higher education in Guangdong Province. The Hengqin district of Zhuhai was formally established in 2009, and it becomes a very special development zone because it is an area of More special district than Special Administrative Region.

\section{B. Culture of Macao}

Macao and Zhuhai are land-bound closely. Macao is an international city of the west coast of Pearl River Delta and one of the two Special Administrative Regions in China so far. Macao is a key point of fulfilling the cause of One Country Two Systems in China and in relation to the success or failure of it. The particular city background, the unique development history and the extraordinary political significance makes Macao form a particular diversified culture.

Macao has diverse culture of combining eastern and western characteristic of civilization. From the Portuguese occupying Macao to the Reform and Opening-up of new China, Macao avoided wars for more than 400 years fortunately while the surrounding areas happened for countless times. Hence the integrity of culture and history was preserved in Macao. The culture of Macao includes the characteristic of not only the Chinese culture and the Portugal culture, but also the culture of South of the Five Ridges, the Confucian culture and multiple religious culture. In spite of synthesizing multiple cultural elements and having all kinds of connections with other culture, the culture of Macao has its own independent characteristic and unique temperament.

Macao has port culture of combining Chinese and foreign style. In 1630s Macao became an international trade port. For more than 300 years before opening of the Hong Kong, Macao was the international entrepot trade hub of the Far East and had a plurality of international ocean routes around East Asia, Southeast Asia, the coast of India Ocean, Africa and Europe. In the process of long-term international economic and trade, cultures around the world mixed together in Macao and the diversity port culture of Macao came into being.

Macao has gambling culture of dominating the market. Macao is lack of land and resource; what's more Macao doesn't have a deep water port. With the Portuguese losing the advantage, the opening of Hong Kong and the improvement of navigation technology, Macao gradually lost the key position of entrepot trade. For survival, Macao had to shift the economy focus to the gambling industry. After nearly 160 years of development, the gambling industry has become the mainstay of Macao economy. Although some scholars have put forward the diversification of the economy of Macao in recent years, the reality that the gambling industry occupies the main status cannot be changed in a certain period. The prosperous tourism industry seemly depends upon the gambling industry to survival actually.

\section{Relations of Zhuhai-Macao Culture}

Zhuhai and Macao are close to each other not only in geographic area but also in emotional exchanges and cooperative development. Both of them interact and affect each other as well. Accordingly there are many similarities in the culture of Zhuhai and Macao. The marine culture of Zhuhai and the port culture of Macao have a lot in common. In the process of historical development from ancient times to the present, both of them shared many of the same experience. The open culture and special region culture of Zhuhai originates from the reform and opening-up policy of China and the return of Macao, which drives the closer cooperation and common development of Zhuhai-Macao.

However, there are many differences in the culture of Zhuhai-Macao. Since the opening of Macao port to the return of Macao, Zhuhai and Macao has been practiced in different political systems, which leads to the inevitable differences between the two cultures. But it is precisely because of the differences so that Macao is particularly special. To be able to attract the people around the world, it is the special Two Systems of the One Country Two Systems policy. Therefore the interactive cooperative development of Zhuhai-Macao needs to be based on the common aspirations and seek cooperation opportunities, and needs to maintain the differences and seek particular characteristics.

\section{STUDY OF BIG DATA TECHNOLOGY AND THE INTERACTIVE COOPERATION DEVELOPMENT OF ZHUHAI-MACAO}

\section{A. Important significance of Zhuhai-Macao Cooperation}

Zhuhai-Macao Cooperation has a special position and important role in the Chinese political reform and economic development. It is not only the first district of China's economic system reform but also the experimental field of China's political system reform. Moreover, it is not only the breakthrough point of the development of local economy but also the key point of the practice of One Country Two Systems The healthy interactive development of Zhuhai-Macao Cooperation is an important part in the great cause of the practice of One Country Two Systems successfully. In this way the validity and the superiority of the One Country Two 
Systems can be reflected fully. Furthermore, it can provide an important reference and instructive for straightening out the question of Hongkong and settling the problem of Taiwan. In addition, it can not only lead the sustained stable all-round economic development of west coast of the Pearl River Delta, but also promote the equilibrium coordinate development of the internal of the Pearl River Delta and drive the in-depth cooperation of the Greater Pearl River Delta region.

Since the return of Macao, the governments from local to central attach much importance to the Zhuhai-Macao cooperation gradually. The high-level coordination system is established, the cooperation details have been strengthened, and a series of policies has been made continuously. With the reform and opening-up deepening the cooperation innovation, Zhuhai-Macao cooperation develops from capital, technology, energy, human resources to business services, economic and trade cooperation, major projects, port clearance, culture and education, talents training and so on. The framework of Zhuhai-Macao cooperation tends to be more reasonable, and the scope of it expands by degrees. In 2011, China's State Council formally approved that the Hengqin District implement the policy which is preferential more than Special Economic Zones[4]. The preferential policies include a series of low and convenient tax, customs, industry, finance, land leasing etc.

To Zhuhai-Macao cooperation, the central government attaches great importance, the Zhuhai-Macao government drives actively, the enterprises collaborate energetically, the people support eagerly and the experts and scholars study diligently. So Zhuhai-Macao cooperation has made breakthrough progress in cooperation level from low-end to high-end, the cooperation range from partial to full, the cooperation degree from decentralized to centralized, the cooperation object from civil to government, and the cooperation study from abstract to concrete. The theoretical research and concrete practice of the strategies of ZhuhaiMacao interactive development also achieved fruitful results, which plays an important role and exerts great influence in guiding and promoting stable healthy economic development of Zhuhai-Macao.

\section{B. Study on Big Data mining and Zhuhai-Macao interactive cooperation development}

In Big Data era, the network technology and application changes with each passing day, the amount of information is very great, the content of information is extremely rich and the data expands rapidly. According to the monitoring statistics of International Data Corporation (IDC), the global total amount of data has reached $1.8 \mathrm{ZB}$ (1ZB is equal to 1 trillion $\mathrm{GB}$ ) in 2011 , and it is expected that the amount will be $35 \mathrm{ZB}$ by 2020 [5]. For the study of Zhuhai-Macao interactive cooperation development, there are the Big Data analysis problems facing the mass data and information as well. There is no doubt that the Big Data mining technology must be used so as to adapt to the situation and requirement of the Big Data era.

About the amount of information, since the return of Macao, the numbers of the related research findings on Guangdong Macao, Zhuhai Macao, Hongkong Macao and
One Country Two Systems are very numerous. Taking the China Knowledge Resources Database of cnki.net as an example, time condition being set from 01-01-1997 to 12-312013, content retrieval conditions being set as theme, title and full text, searching terms being set as Macao, Hongkong and Macao, searching databases being set as Academic Journals, PhD Thesis, Outstanding Master's Degree Thesis, China Important Conference Papers and International Conference Papers (except for Important Newspapers, Yearbook and Tool Book Database), the retrieval results as shown in table 1.

TABLE I. THE RETRIEVAL RESULTS (UNIT: ITEMS)

\begin{tabular}{|c|c|c|c|}
\hline Content & Theme & Title & Full Text \\
\hline Macao & 15535 & 7122 & 179463 \\
\hline Hongkong Macao & 7065 & 1943 & 125749 \\
\hline Subtotal & 115825 & 37029 & 1407831 \\
\hline \multicolumn{4}{|c|}{$\begin{array}{l}\text { Note 1: The searched website is cnki.net. } \\
\text { Note 2: The date is from } 01-01-1997 \text { to } 12-31-2013 \text {. } \\
\text { Note 3: The retrieval time is } 06-24-2014 \text {. }\end{array}$} \\
\hline
\end{tabular}

About the construction of information database, the study of Zhuhai-Macao institutions are more and more today, but there is no open sharing complete resource database of the research findings about the study of Zhuhai-Macao. This situation seriously hinders the development of Zhuhai-Macao research on modernization, informationization and scientification. At present, the research mode of the most research institutions still is in the traditional level. They merely rely on social science researchers or liberal arts professionals, and less or even not use the information technology. Some research institutions only to establish a simple static website and a little better research institutions just build simple query website with ordinary functions.

We think studying the Zhuhai-Macao cooperation in the age of Big Data needs to realize the innovation of study direction, study mode, study platform and study principles. Firstly, based on the Big Data mining technology, establish the comprehensive systematic clear attribute label and associated relation database, so that the massive Zhuhai-Macao information can be analyzed entirely systematically and synthetically. Secondly, combine the information technology and social science closely, use data analysis, data statistics and data mining scientifically, and apply the research methods of the social science to study it deeply and comprehensively. Thirdly, construct such a platform as collecting data and converting format effectively, processing data quickly, storing information intelligently, and learning analysis rules autonomously with integrated management and analysis. At last, respect science, data, experts and grassroots, rely on scientific data analysis and data statistics, and combine the expert opinion to make the evaluation and analysis reasonably. 


\section{PROBLEMS AND COUNTERMEASURES ON INTERACTIVE ECO- SOCIAL DEVELOPMENT OF ZHUHAI-MACAO}

From the above analysis based on the Big Data mining technology and considering the concrete practice, we found some problems in the research of the interactive eco-social development of Zhuhai-Macao, and put forward some strategies and suggestions to solve the problems.

\section{A. Transformation of Zhuhai-Macao Government Slowly}

The Zhuhai-Macao government needs to play its due role in cooperation, but the views of Government Led dominate all the time. With the deepening of the cooperation, the views perpetuate the planned economic system to a certain extend and cannot adapt to the interactive development situation gradually in the new period. Under the condition of market economy, the cooperation in the Zhuhai-Macao government is in the macro level, policy level and institution level and the government should play the role of macro statistics, data analysis and policy guidance and so on.

We suggest the Zhuhai-Macao government should transform quickly to adapt to the development requirements in the new era. At present, the main roles of government is to guide, support and grasp the direction rather than direct, operate and do it by itself. Any government should play a supporting and coordinating functions role mainly, just like paving and bridging. The main mission of the government is to make the policies, rules and regulations which can be practiced, operated and applied, being based on legitimate, reasonable and appropriate principle, according to open, fair and equitable way, fully understanding the aspirations of business and people, and carefully analyzing the suggestions of experts and scholars. So the Zhuhai-Macao government should assist the enterprises, serve the people, develop the economic, improve people's livelihood, increase employment, promote social equity, deduce the social contradiction and lower social risk etc.

\section{B. Cooperation of Zhuhai-Macao Government poorly}

About cooperation Zhuhai-Macao government needs overall ideas and interactive cooperation consciousness, but in solving some concrete problems in reality, the situation appears that the government acts according to its own free will and lets it run its own business. For example, the competing between Zhuhai Airport and Macao Airport, the conflict of Zhuhai-Macao 24-hours customs, the contradiction of the development direction of Cross-border Industrial Zone, the controversy of the place of the Hongkong Zhuhai Macao Bridge, and the land contradiction of Macao University Hengqin Campus [6]. Causing these conflicts and contradictions, one of the reasons is because of being lack of sufficient communication and opinion exchange in the process of cooperation, and the other is because of being based on different standing points and maintaining their own interests. In the final analysis the Zhuhai-Macao government lacks the concept of overall situation in some aspects and does not analyze the problems from the national and society level and long-term development perspective.
We suggest the Zhuhai-Macao government should strengthen communications to conform to the overall requirements. The Zhuhai-Macao government should improve the concept of the overall situation, enhance overall consciousness, pay more attention to the interactive cooperation, avoid administrative fragmentation, resolve contradictions, reduce conflicts, eliminate disputes and introduce proper competition. The Zhuhai-Macao government should hold a forum for experts and adopt their opinions, promote the communication of enterprises and listen to their voices, know the opinions of people and solve their problems. On this basis, the Zhuhai-Macao government should synthesize various kinds of conditions and factors and make the policy which is suitable for the two respective characteristics with The Same Trade Complementing Mainly and Competing Auxiliary.

\section{Integration of Zhuhai-Macao Incautiously}

In recent a year the view of Integration of Zhuhai-Macao or City Integration of Zhuhai-Macao is put forward widely, which seems that the Zhuhai-Macao cooperation cannot be successful without it. In fact the Integration cannot blend into one harmonious wholly and the City Integration cannot be the same completely. The Integration or City Integration has its reasonability and scientificalness, but what will be integrated is to need to consider seriously. The cooperation of ZhuhaiMacao is not to duplicate a new Macao, and is not expanding the Macao simply. It is to be the complement and enhancement of Macao, and to be the improvement of One Country Two Systems.

It is obviously not suitable that Zhuhai and Macao do the same thing. This will lead to malicious competition and interest conflict between them. We need to think of calmly and carefully that what the real meaning of Integration or City Integration is and cannot make the same projects like a swarm of crazy bees. During the Integration and City Integration in the cooperation of Zhuhai-Macao, the Zhuhai-Macao government needs to pay more attention to strengthen communication and coordination, seeks to help each other mutually and beneficially, and finds the harmonious and winwin way.

\section{Talents Management of Zhuhai-Macao Insufficiently}

Talent is the core competitiveness of scientific development. The cooperation of Zhuhai-Macao is inseparable from the advanced talent management, the comprehensive talent planning, the scientific talent cultivation, and the reasonable talent introduction. From the perspective of talent management, the talent policy and system have not only the reward and incentive measures, but also the punishment measures and quality audit system. From the point of view of talent planning, it is to need extensive participation, multiple levels, comprehensive range and considering thoroughly. That is to say, making talent planning not only have should the guidance of government and experts, but also have should enterprise and social participation.

From the perspective of talent cultivation and talent introduction, it is important to introduce shortage talent, special talent and senior talent. But it is not reasonable to think 
that foreign monks recite good scriptures. Training and using local Monk should be paid more attention to. Cultivating and employing local talents should be considered first and foremost in the cooperation of Zhuhai-Macao. It will help to promote the development not only of the education industry of Zhuhai-Macao, but also of scientific technology research and high-tech.

\section{CONCLUSIONS}

It has important significance to study the regional culture and interactive eco-social development of Zhuhai-Macao in Big Data era. First of all, the Zhuhai-Macao cooperation and development needs to be based on their respective cultural characteristics and consider their own distinguishing cultural features. Secondly, the research of Zhuhai-Macao cooperation and development in Big Data era needs to utilize the Big Data mining and other information technology fully. Finally, in the new period of Big Data, we should do research scientifically, analyze deeply and adjust the coping strategies continuously to adapt to the world changing constantly.

In short, with the continuous enhancement and deepening of Zhuhai-Macao cooperation, new problems and new challenges come with new opportunities. Analyze and adjust the problems and shortcomings of the interactive development strategies about Zhuhai-Macao cooperation further in order to clarify the situation scientifically, position the reason accurately, overcome the difficulties hand in hand, solve the problems quickly and make up the insufficiency timely, which makes the cooperation and eco-social development of ZhuhaiMacao maintain the healthy sustainable improvement.

\section{REFERENCES}

[1] Li Jing, "On the Zhuhai-Macau Culture and Cultural Industry Development," in Journal of Zhuhai Administrative College of the Party School of CPC Zhuhai Municipal Committee, vol.44, issue 4, pp. 50-55, August 2010. (In Chinese)

[2] Wang Yuqi, "Review and Some Thoughts of Zhuhai and Macau Cooperation," in Journal of Zhuhai Administrative College of the Party School of CPC Zhuhai Municipal Committee, vol. 34, issue 6, pp. 51-54, December 2008. (In Chinese)

[3] Li Jing, "On the Zhuhai-Macau Culture and Cultural Industry Development," in Journal of Zhuhai Administrative College of the Party School of CPC Zhuhai Municipal Committee, vol.44, issue 4, pp. 50-55, August 2010. (In Chinese)

[4] Yang Zhihui, "Innovative Research on Services Channels to Science Technology of Hengqin under the Informationization Background," in Science and Technology Management Research, vol. 314, issue 16, pp. 94-98, August 2014. (In Chinese)

[5] Jiang Feng, "Global Total Amount of Data 1.8ZB in 2011, when Big Data to Knock," in The People's Daily, pp. 10, 2012-12-24. (In Chinese)

[6] Cai Hui, "How to Develop the Zhuhai-Macao Closer Partnership from the Five Story," in China Population, Resource and Environment, vol. 21, pp. 185-186, 2011. (In Chinese) 